Nice and not so nice

\section{Nice and not so nice}

\section{John Harris}

M ichael Rawlins and Andrew Dillon start their defence of Nice in fine polemical style, unfortunately polemics is all they have to offer. They totally fail to justify the Nice proposals on dementia treatments nor do they make any more plausible than formerly their use of the notorious QALY. They say:

Harris's recent editorial, It's not NICE to discriminate, is long on both polemic and invective - but short on scholarship. He offers nothing to illuminate the debate about allocating healthcare in circumstances of finite resources; he has no understanding of the quality adjusted life year (QALY) and its use in health economic evaluation; and he makes ill-researched, unsubstantiated and offensive charges against the Institute and its advisory bodies.

Accusations are easy to make, difficult to substantiate. There are a number of claims here, only one of which is true. It is true that my editorial was robust, polemical if you like, but editorials are not the same as research papers and these are important issues which deeply affect real lives. Although Rawlins and Dillon affect to take the high ground their own article contains even more vigorous and much more personal invective than my editorial, I make no complaints. But as to the rest of what they say, well, let's just see!

They claim I offer nothing to illuminate resource allocation and that I have no understanding of the QALY. Both of these claims may well be true, but nothing they say goes any way to support these claims or even towards making them plausible. I have studied and written about the QALY for almost 20 years $^{1-15}$ and Rawlins and Dillon show no evidence of any awareness or indeed any understanding of the issues, whether discussed by me (in 15 papers and many more popular pieces) or by others who have found the QALY highly problematic. True, these papers have been criticised, but the arguments they contain have never been refuted, certainly not by Rawlins and Dillon. In my editorial I provided arguments for all claims made, none of which are engaged by Rawlins and Dillon. Let's get down to cases.

Rawlins and Dillon seem to think that unless I (or anyone) is prepared to offer solutions to the problem of distributing health resources under conditions of scarcity we are not entitled to criticise the work of those, like NICE, who do. Rawlins and Dillon claim: "He offers nothing to illuminate the debate about allocating healthcare in circumstances of finite resources;... Harris, himself, whilst accepting that resources should not be wasted, has offered nothing that approaches a workable solution.... Some constructive suggestions, rather than sniping from the sidelines, would be appreciated." As it happens I have had quite a lot to say about these issues ${ }^{1-}$ ${ }^{15}$ but supposing I hadn't or that these solutions are wrong or unworkable, still what Rawlins and Dillon claim is absurd. They suggest that no-one can criticise a proposed solution to a problem unless they have a better one to offer! That would be like saying that it is somehow illegitimate to criticise a proposed treatment for cancer on the grounds that a) it didn't cure or palliate cancer and b) it actually made cancer patients worse off, unless those critics had themselves a better cure for cancer to offer! The point is that NICE's recommendations on Alzheimer's drugs will deny people palpable benefits and offer no better (or comparable but cheaper) alternatives. Indeed if NICE followed the absurd advice of their Chair and Chief Executive, they would have no basis for rejecting the Alzheimer's drugs since they themselves offer no better alternatives, indeed they do worse than "snipe from the sidelines", they propose, from the sidelines, to leave patients untreated.

In the face of a lack of consensus amongst moral philosophers, NICE has adopted the principles of procedural justice - "accountability for reasonableness"

I accept that there is no consensus among philosophers about distributing scarce resources. I have never suggested otherwise. One obvious lesson is that such exercises are fraught with difficulty. However, procedural justice does not solve this problem, rather it seeks to make the process of failing to solve the problem transparent, and to demonstrate the reasonableness of the process and only via the reasonableness of the process the reasonableness of the product of that process, inter alia, so that those who make decisions (such as NICE) can be easily held to account. "When we lack consensus on principles that tell us what is fair, or even when we have general principles but are burdened by reasonable disagreements about how they apply, we may nevertheless find a process or procedure that most can accept as fair to those who are affected by such decisions. That fair process the determines for us what counts as a fair outcome... Our approach in this book is to recast the problem of limit setting as a question about how decisions about limits should be made. Specifically under what conditions should society grant authority to individuals or institutions to set limits to health care?"16 The Daniels/Sabin approach thus makes the reasonableness of the process crucial. This exchange is centred on the question of whether QALYs are or are not an unreasonable part of that process and hence as to whether or not they vitiate the reasonableness claimed for the process. Rawlins and Dillon fail to see the irony of complaining when they are in fact held to account.

\section{QALYS, AGEISM, AND LIFE EXPECTANCY}

NICE's preferred approach, to economic evaluation, is cost utility analysis; and the Institute uses estimates of the quality-adjusted life year (QALY) as its principal (though not only) measure of health gain. The QALY is simple in concept. It ranks health-related quality of life on a scale of zero (dead) to one (full health), and multiplies this by the time (years) during which this improved state of health is enjoyed. If one form of treatment is superior to another, but costs more, the incremental cost effectiveness ratio provides an expression of the additional money required to achieve an improvement in health...

Rawlins and Dillon go on to affirm that: "The QALY is not... inherently ageist".

Here it is Rawlins and Dillon who clearly have no understanding of QALYs. One of the chief architects of the QALY described it as "a simple, versatile, measure of success, which 
incorporates both life expectancy and quality of life" ${ }^{\prime 17}$ It is the fact that younger people usually (though not always), have more life expectancy to gain from treatment than older people that makes the QALY "inherently ageist". One wants to ask which of the two words "life" and "expectancy" do Rawlins and Dillon not understand?

True, Rawlins and Dillon give some examples in which QALY's are neutral, or might indeed favour the aged in the distribution of health resources. Unfortunately Rawlins and Dillon are not paying attention. In my editorial and indeed in everything I have written on QALYs, I distinguish two ways in which QALYs may be used. As I explicitly noted in my editorial:

\section{The QALY combines life expectancy after treatment with measures of the expected quality of that life. There are two ways in which QALYS can be used. They might be used to determine which of rival therapies to give to a particular patient or which procedure to use to treat a particular condition, in short which of two different treatments is the more cost effective, better for patients, better for society. However, QALYS are also used to determine not which of rival treatments to give a particular patient or group of patients, but whether or not to offer any treatment at all to some patients, or whether to offer a particular treatment to some patients even when no alternatives are preferred.}

I have always affirmed that QALYs are often appropriate for the first use but most usually vicious and totally inappropriate in the second. However, in every case QALYs are indeed, and by definition, inherently ageist and also favour those with the greater life expectancy regardless of age. This must be the case because length of lifetime to be gained, is both valued and built in to the way QALYs are calculated.

The more life years gained from treatment the more "effective" the treatment, that is what QALYs say, which is why they inevitably 'prefer' more lifetime whether possessed by the younger candidates or those who happen to have more lifetime to gain from treatment.

More lifetime is clearly beneficial when choosing between treatments, but usually vicious and discriminatory when choosing between patients, because different people benefit from the extra years on offer. Rawlins and Dillon have highlighted some cases where QALYs in fact favour older patients but this does not show that they are not inherently ageist, only that there are some cases where the sums come out differently and favour older patients. The presence of some black officers is no evidence that a police service is not "inherently racist", the existence of some cases where QALYs may favour older patients is likewise no evidence that they are not inherently ageist. QALYs are of course likely to benefit older patients in a range of treatments where there is either 1) no effect of the treatment on length of life and the time in which the treatment works is so short that natural differences in length of life do not matter (for example, analgesia for acute pain), 2) where old people are significantly more likely to die if not treated than young people or, 3) where old people are significantly more likely to require costly support if not treated than young people.

The bottom line is that in QALYs and in NICE's "preferred approach, to economic evaluation," and "its principal (though not only) measure of health gain", life years play a pivotal role and therefore if QALYs play any part at all in choosing between patients then they will inevitably tend to weight the choice towards greater life expectancy (usually, though not always) possessed by the younger candidates for treatment.

\section{QUALITY OF LIFE}

Again, when choosing between patients rather than treatments, the "QA" dimensions of QALYs tend to be vicious. Imagine twin sisters, Jackie was born paralysed from the waist down and Jill was born healthy. Now in their thirties, Jackie has established a life for herself that she finds worthwhile and satisfying. So has her twin. Both agree, however, that Jackie's quality of life is objectively substantially lower and both agree that Jackie's life expectancy is substantially the lesser. Both, we will suppose are now involved in an accident and resources available can only treat one before death strikes them both. Or, both are stricken with an illness and while treatment could restore both to the status quo ante, there is only one intensive care bed available or only one course of drug therapy and hence, only one will survive. It seems to me that not only is it unethical to choose between them. There is no rational basis for so doing. ${ }^{18-22}$ Both want to live, both have lives they find worthwhile. If we believe that we should prefer to rescue those where treatment makes more of an improvement in quality of life then we should surely rescue Jill. Suppose that quality of life is measurable numerically, (for reasons not immediately relevant I don't believe any numerical ratings of this sort can be meaningful) and suppose it is agreed that Jackie's quality score before illness or accident was 6 and Jill's was 10. Then to rescue Jill makes a difference of 10 , while saving Jackie yields only a score of 6. It is surely the treatment and the rescue that makes this difference because without out them Jackie and Jill would score zero. They would be dead. This shows that the QALY scores of the treatment are not meaningfully separable from the QALY scores of the individual treated, if what matters is the QALY expectations of the individual after treatment. Indeed, how could it be otherwise, for the point of high QALY scores of treatment is to deliver high QALY scores to individuals. The same is of course true of life expectancy.

Once grant that part of the justification for using QALYs as a prioritising principle is that we ought to maximise quality as well as quantity of life, then it clearly defeats the object to draw a distinction between quality or quantity, which is independent of treatment and quality delivered by treatment where both affect the outcome. The effects, whether measured in QALYs or not, of treating someone successfully for lethal illness $\mathrm{x}$, when he will die a week later of $y$, are the same as a treatment for $\mathrm{x}$, which will only yield one weeks' remission.

The temptation to think otherwise derives from confusing the choice between different therapies for the same patient and between different patients for the same therapy. In the former case it is the QALYs derivable from treatment that matter because the background health state and life expectancy are a constant. In the latter case, if life expectancy and quality are relevant at all (which I doubt) it must be the total QALY score of the person following treatment that is the determining factor.

The point about the issue of age and life expectancy also emerges clearly from a mistake Rawlins and Dillon make about the meaning of what it is to "take something out of context".

They suggest I am:

also guilty of misrepresentation. Mr Justice Mars Jones did indeed state: "However gravely ill a man may be ....he is entitled in our law to every hour....that God has granted him. That hour or hours may be the most precious and important hours of a man's life. There may be business to transact, gifts to be given, forgiveness to be made, 101 bits of unfinished business, which have to be concluded" 
By a curious chain of coincidences one of us (MDR) was present in Court, as an expert witness, when these words were uttered. But Harris has taken them totally out of context. They were spoken during Mars Jones' summing up to a jury in the trial of a general practitioner accused of the attempted murder of a man who was mortally ill from lung cancer. The case was about as far removed from ageing or resource allocation as could be imagined.

Rawlins and Dillon show that they do not understand the meaning of the term "relevant context". Here, the context is the connection between life expectancy and the value of life, not whether or not the shortness of the life was caused by cancer, or the operation of QALYs or by the actions of a criminal defendant. The point is that shortness of life expectancy, (fewer QALYs, ) does not diminish the value of a life, it is on this that Mars Jones and I agree.

It is easy to see why, contra Rawlins and Dillon, the relevant context cannot be confined to the narrow social, political, or legal context in which remarks are made. If it could be so confined every time someone quoted the American Declaration of Independence, Magna Carta, The Sermon on the Mount ,or the Ten Commandments and pointed contemporary relevance they would be "taking things out of context". The context in which I quoted Mars Jones was the context in which he made his judgement. Mars Jones was making a general statement about the value of life in English law and morality and the fact that life expectancy does nothing to diminish that value. In this case, the relevance of life expectancy to the value of life in that a person is entitled to "every hour...that God has granted him" because "that hour or hours may be the most precious and important hours of a man's life", these are remarks about the connection between life years or in this case "life hours" and the value of a life, the fact that they were said in the trial of a man accused of attempted murder does not mean that they have been "taken out of context".

This is the heart of the issue about QALYs and it is not just regrettable but tragic that Rawlins and Dillon totally fail to see its relevance and seek to evade the issue by alleging I have taken Mars Jones's remarks out of context. Life expectancy - life years gained from treatment, are irrelevant when choosing between candidates for treatment precisely because, as Mars Jones so eloquently points out, the value of a life is not proportionate to the amount of unelapsed time that life contains. My point is that this is true, not only, if Mars Jones is right in our law, but in our morality, and that therefore the life years element of the QALY is not only irrelevant, but contrary to morality when applied to decisions as to whether or not to offer treatment to particular patients, as in the Alzheimer's drugs case. This, after all, was the subject of my editorial.

The example of the twins shows this is also true of the quality of life dimensions of QALYs. It follows that QALYs are only contingently relevant to choices as to whether or not to treat patients (rather than to choices as to which of rival treatments to offer them). So far from it being appropriate - right and proper - that "NICE's preferred approach, to economic evaluation, should be "cost utility analysis" it is quite improper and exceedingly immoral, and if Mars Jones is right it is also contrary to Legal Principles.

Finally it is worth noting that Rawlins and Dillon accuse me of holding positions that I do not hold and have never held, but rather positions that their failure to take seriously what I have said leads them falsely to attribute to me.

As Harris points out, the Institute's guidance recommends that IVF should be provided by the NHS, to infertile women aged between 23 and 39 years. The evidence shows that the success rate in older women is very small. Harris, though, suggests that this advice is inappropriate; and that the NHS should offer the chance of IVF to as many women as possible.

This is the point, of course, where Harris leaves the real world and enters a parallel - value and cost free - universe. For if the NHS lor any other healthcare system in the world) were to go along his route, and provide everything anyone wanted, it could consume almost the entirety of a nation's gross domestic product with nothing left for any other form of public (or, for that matter, private) expenditure.

I have never said nor written, nor do I believe, that the NHS, nor any health care system could or should "provide everything anyone wanted". When I say the choice is between maximising the number of take home babies and maximising the chance to offer IVF to as many women as possible I am pointing out different moral priorities in allocating a given budget, whatever that budget is. I have also made suggestions about how to arrive at a given budget, but that is another issue. ${ }^{23}$

\section{Despite Harris's assertion to the contrary, the issue of how age might be considered in the allocation of healthcare resources is disputed. NICE has taken a principled posi- tion...}

I made no such "assertion to the contrary" but it is perhaps on this occasion partly my fault that I have been misinterpreted. For the record I do not believe nor have I said that the issue of how age and life expectancy function is undisputed. I know it is disputed, not least by me! What I actually said was: "The reason for outlawing race discrimination must be that it is clearly perceived by all to be absolutely morally unacceptable. And yet the same holds for age discrimination as for race discrimination. Both race and age are in some circumstances "indicators of benefit or risk", some ethnic groups are at greater risk of certain genetic conditions than others for example, either both types of discrimination warrant execration as unjust or both should be celebrated as justifiable discrimination on QALY grounds and therefore required to fulfil NICE purposes." My fault perhaps, but the statement "And yet the same holds for age discrimination as for race discrimination" refers and is intended to refer to the fact that both age and race are in some circumstances "indicators of benefit or risk" not to the phrase "perceived by all to be absolutely morally unacceptable". I am not claiming any universal agreement about the unacceptability of age discrimination. Although also for the record I find it unacceptable for reasons I have given. ${ }^{1-15}$

This is the point on which I believe there needs to be engagement and debate. What is the role of age and life expectancy in making decisions which determine who will live and who will die, who will receive medical treatment and who will not? Rawlins and Dillon say "NICE has taken a principled position..." I do not doubt it, but principled positions are not necessarily either right or good. It is not a great virtue to espouse the wrong principles and one of the purposes of this journal is to explore the appropriateness of principles used in Medical Ethics. Contrary to what Rawlins and Dillon appear to believe, I made no personal attacks in my editorial, I was criticising NICE and its principles, I do not doubt that Rawlins and Dillon and all their advisors are good men and women acting in good faith in difficult circumstances. That is not the point. 
The point is that the principles and policies NICE have espoused and recommended in this case are calculated to have very bad consequences for thousands of patients and good consequences for none. Again Rawlins and Dillon are not paying attention. They say: "Harris also stated, ${ }^{1-15}$ in his editorial, that the preliminary conclusions of the Institute's appraisal committee on Alzheimer's drugs was "wickedness or folly or more likely both". His use of invective is contemptible". I emphatically did not say this, what I in fact said was: "It is difficult to think of this as anything but wickedness or folly or more likely both." This was an invitation to NICE to demonstrate that there are other ways of thinking about it, not a claim that it must be thought of in this way.

I accept there is no intended wickedness, but it is surely folly to apply bad principles in discredited ways.

NICE represents another worrying danger. I am not convinced it is playing a role that should be played at all. NICE is the "National Institute for Clinical Excellence", implying that its brief is to promote clinical excellence, not to (sometimes) stand between patients and the only available treatment. NICE also stands between patients and all treatments it considers in another way. Because of the time NICE takes to review drugs or treatments that are already available, patients are often forced to wait up to 2 years or more before NICE gets around to finalising its approval. These delays add considerable costs to the patients and arguably to the health care system. Inevitably some patients will die before the treatment that might have saved them or made their last days more comfortable is permitted. This notwithstanding, my own view is that in the case we have been discussing, if there is a proper role for NICE, it is to say that it is not a matter of clinical excellence to determine that the only available treatment should not be funded by the NHS. This is not a matter, (as I have argued, in my editorial and in many places for nearly twenty years) on which QALYs can be any help at all. If it is a question to be decided it is a question in two parts. One part is the issue of whether or not extra resources should be made available to the NHS. The other is, if we have to accept a limited budget, how does say, the provision of dementia treatments, rate in moral importance against the other priorities of the NHS and how should such conflicts be resolved? This is something that I have tried to say something about. I may have failed to offer anything to illuminate this debate but it cannot be said that I have not tried to do so. What can definitively be said is that Rawlins and Dillon have offered nothing which approaches either a discussion of the points I have made, either in the editorial or in this journal or elsewhere, let alone a rebuttal of them.

NICE is a public body, making decisions which affect the lives and life chances of real people, that is a hot place to be, and those who occupy such a place do so from choice, unlike the patients whose fate their decisions determine. As this exchange demonstrates, those who write in journals also voluntarily occupy a hot place, a place where what they say and do is not only open to public scrutiny and criticism but which positively invites it. Sometimes heat sheds light, I hope that this is one of those occasions. The phrase "if you can't stand the heat, stay out of the kitchen" is often attributed to U.S. President Harry Truman, but I have been unable to find a definitive source for this quotation.

\section{J Med Ethics 2005;31:685-688. \\ doi: 10.1136/jme.2005.014134}

Correspondence to: John Harris, The Centre for Social Ethics and Policy, Institute of Medicine Law and Bioethics, School of Law, University of
Manchester, Williamson Building, Oxford Road, Manchester, M13 OJH; john.m.harris@ man.ac.uk

Received 23 September 2005

Accepted for publication 23 September 2005

\section{REFERENCES}

1 J Harris. Rationing Life. The Health and Social Service Journal, June, 1986

$2 J$ Harris. QALYFying The Value of Life. J Med Ethics 1987;13:117-23.

3 J Harris. Life: Quality, Value \& Justice. Health Policy 1988; 10:259-66.

$4 \mathrm{~J}$ Harris. The Ethics of Resource Allocation. $J$ Epidemiol Community Health 1990;44.

5 J Harris. Unprincipled QALYs.J Med Ethics 1991;17:185-88.

$6 \mathrm{~J}$ Harris. Is gene therapy a form of eugenics? Bioethics. 1993;7: 178-187, [Reprinted in R S Downie, ed. Medical Ethics Dartmouth, Aldershot, 1996.].

7 J Harris. Does Justice Require that we be Ageist? Bioethics 1994:8:74-84.

$8 \mathrm{~J}$ Harris. Double Jeopardy and the Veil of Ignorance. J Med Ethics 1995;21:151-7.

9 J Harris. Would Aristotle have played Russian Roulette? J Med Ethics 1996;22:209-215.

10 M Brazier, J Harris. Public Health and Private Lives. The Medical Law Review 1996;4:171-92.

$11 \mathrm{~J}$ Harris. Could we hold people responsible for their own adverse health? J Contemp Health Law Policy 1996; 1:100-6.

$12 \mathrm{~J}$ Harris. What is the good of health care? Bioethics 1996;10:269-92.

13 J Harris. What the principal objective of the NHS should really be. BMJ 997;314:669-72, [Reprinted in Bill New, ed. Rationing: talk and action in health care. London: BMJ Publishing Group, 1997:100-6.]

$14 \mathrm{~J}$ Harris. Justice and Equal Opportunities in Health Care. Bioethics 1999:13:392-405.

$15 \mathrm{~J}$ Harris. The Age Indifference Principle and Equality. Camb Q Healthc Ethics 2005;14:93-9

16 N Daniels, JE Sabin. Setting Limits Fairly. Oxford: Oxford University Press, 2002:4.

17 Williams A. The value of QALYS. Health and social service journal 1985

18 J Harris. Rationing Life: Quality or Justice? In M Ockelton, ed. Medicine, Ethics And Law, ARSP, Beiheft Nr. 32. Steiner 1987:104-12.

19 J Harris, EQALYty In: Peter Byrne, ed. Health Rights \& Resources, King's Fund and OUP. 1988:100-28

20 "More, Better Justice" in Sue Mendus, Martin Bell, eds. Philosophy And Medical Welfare, Cambridge, Cambridge University Press, 1988:75-97.

21 J Harris. Rationing Life. The Health and Social Service Journal 1986

22 J Harris. QALYfying The Value of Life. J Med Ethics 1987;13:117-23.

$23 \mathrm{~J}$ Harris. What is the good of health care? Bioethics 1996;10:269-92. 